\title{
Sickness absenteeism of Healthcare Workers in a Teaching Hospital
}

\author{
Maryam Mollazadeh ${ }^{1}$, Maryam Saraei ${ }^{1}$, Ramin Mehrdad $^{1}$, Nazanin Izadi $^{*}$ \\ ${ }^{1}$ Center for Research on Occupational Diseases, Tehran University of Medical Sciences, Tehran, Iran
}

*Corresponding Author: Nazanin Izadi, M.D., Associate Professor, Center for Research on Occupational Diseases, Tehran University of Medical Sciences, Tehran, Iran. Tel: +98-021-66405588, Fax: +98-021-66405588,

Email: Nazanin.izadi @gmail.com

Received October 4, 2017; Accepted November 28, 2017; Online Published January 28, 2018

\begin{abstract}
Background: Absence from work for health reasons is known as "sickness absenteeism". Frequent sick leave is a major concern to any organization, especially hospitals.

Objective: This study analyzed the extent and causes of sickness absenteeism in a teaching hospital and evaluated its corelation with demographic and occupational factors.

Methods: In a cross-sectional study, data was extracted from computerized records regarding sickness absenteeism of healthcare workers (HCWs) in the Occupational Health Department of a teaching hospital in Tehran. Studied variables included demographic characteristics, occupational factors, and causes of sickness absenteeism. The sickness absence rate (SAR) and absence frequency rate (AFR) in the study period were calculated. Chi-square and Mann-Whitney tests were used for the comparison of categorical and quantitative variables, respectively.

Results: In the current study, SAR and AFR were 0.011 and 0.68 , respectively. Job type was the only factor that had a significant correlation with sickness absenteeism. The major disease-causing sicknesses were flu (21\%) and musculoskeletal disorders $(18.9 \%)$.

Conclusion: A significant relationship was found between the nursing group and sickness absence episodes. Flu, musculoskeletal disorders, and infectious diseases were the most frequent causes of sickness absence. Based on these findings, it can be concluded that factors such as availability of the flu vaccine and providing principles of personal protection and infection control can reduce sickness absence due to infectious disease.

Keywords: Healthcare Workers, Absenteeism, Sickness Absence
\end{abstract}

\section{Background}

Absence from work, or absenteeism, is described as the lack of presence when expected at work for any cause. Absence from work due to health causes is called sickness absenteeism. Sickness absence is a significant scale with which to measure the status of a person's health and his potency to work. Absenteeism leads to a loss of productivity. ${ }^{1}$

Sickness absenteeism is divided into 2 types: Short-term (less than 4 days) and long-term ( $\geq 4$ days). Short-term sickness absence has a greater frequency than long-term. It is usually due to less serious illness, whereas long-term sickness absence usually occurs due to serious conditions. ${ }^{2}$

Sickness absenteeism represents the workers' health status; therefore, it is a main public health issue. Additionally, it carries a serious economic burden and imposes higher costs upon organizations and social security systems. The economic burden of sickness absence is considerable, and countries want to reduce these costs. ${ }^{3,4}$

Frequent sick leave is a major concern to any organization, especially hospitals. Healthcare workers (HCWs) are a necessary element in the effective delivery of health services to society. HCWs are exposed to many various health hazards including various infectious agents, contaminated human blood and body fluids, types of equipment, and chemical hazards because of the complex nature of their jobs. ${ }^{5,6}$

Health problems among HCWs could have adverse effects on workplace utility, work efficiency, and quality of patient care, and they it could increase the workload of other staff members, which can lead to dissatisfaction in the workplace. ${ }^{7}$

\section{Objective}

There is limited evidence for an association between demographic or occupational factors and sickness

Copyright $\odot 2018$ The Author(s). This is an open-access article distributed under the terms of the Creative Commons Attribution License (http:// creativecommons.org/licenses/by/4.0), which permits unrestricted use, distribution, and reproduction in any medium, provided the original work is properly cited. 
absenteeism in Iran's healthcare industry. The current study purposed to analyze the extent and causes of sickness absenteeism at a teaching hospital in Tehran and evaluate the association between sickness absenteeism and demographic and occupational factors.

\section{Methods}

This cross-sectional study reviewed data on the sickness absenteeism of HCWs from one of the university hospitals of Tehran University of Medical Sciences in 2014-2015.

Data on the demographic characteristics including age, gender, marital status, number of children, educational level, and occupational factors (employment type, job type, ward, shift work, duration of employment) and causes of sickness absenteeism was collected in this study.

Sickness absence rate (SAR) and absence frequency rate (AFR) in the study period were calculated. SAR was measured as (the total number of sickness absence days/ potential working days) $* 100$. AFR was measured as (the total number of incidents or spells of sick leave in a period/ average number of employees during this period). ${ }^{8}$ There were 290 working days in the study period.

The study population comprised all hospital staff members. Potential subjects were excluded if they quit their jobs during the study period or left their jobs for maternity leave. In this teaching hospital, employees who miss work because of illness should present a medical certificate to the hospital's responsible physician. If approved, the certification is presented and registered with the Occupational Health Department. In this study, data was gathered from the computerized records of the Occupational Health Department and analyzed using SPSS software version 18. Categorical variables were analyzed by the chi-square test, and because of the absence of normality distribution, the Mann-Whitney test was used to compare quantitative independent variables.

\section{Results}

The total number of hospital personnel was 690, of which 180 subjects had sick leave. During the study period, SAR and AFR were 0.011 and 0.68 , respectively. The mean age and standard deviation (SD) of absentees was 35.49 \pm 7.53 years (Table 1). Among absentees, $75 \%$ of them had a bachelor degree and higher. Most participants in this study were female. Higher rates of sick leave occurred among married absentees, and half of them had one or more children. More than two-thirds of sick leave was taken by the nursing group, and about one-third of sickness absence occurred in the ICU, CCU, and emergency ward. Approximately half of the absentees had fixed shift work, and they were officially employed. The major diseases causing sickness absences were flu (21\%) and musculoskeletal disorders (18.9\%).

Table 2 presents the median numbers of sickness absenteeism days based on demographic and occupational characteristics. There were no significant relationships between median numbers of sickness absenteeism days and
Table 1. Demographic and Occupational Characteristics and Causes of Sickness Absenteeism

\begin{tabular}{|c|c|c|}
\hline Variables & & No. $(\%)$ \\
\hline \multirow{2}{*}{ Gender } & Male & $31(17.2)$ \\
\hline & Female & $149(82.8)$ \\
\hline \multirow{2}{*}{ Marital status } & Single & $59(32.8)$ \\
\hline & Married & $121(67.2)$ \\
\hline \multirow{2}{*}{ Children } & No children & $88(49.4)$ \\
\hline & Having children & $90(50.6)$ \\
\hline \multirow{2}{*}{ Education level } & $<$ Bachelor's degree & $45(25)$ \\
\hline & >Bachelor's degree & $135(75)$ \\
\hline \multirow{2}{*}{ Employment type } & Contract & $88(49.2)$ \\
\hline & Official & $91(50.8)$ \\
\hline \multirow{2}{*}{ Job } & Nursing group & $114(63.3)$ \\
\hline & Others & $66(36.7)$ \\
\hline \multirow{2}{*}{ Ward } & ICU, CCU, Emergency & $71(39.4)$ \\
\hline & Others & $109(60.6)$ \\
\hline \multirow{2}{*}{ Shift work } & Rotatory & $87(48.3)$ \\
\hline & Fixed & $93(51.7)$ \\
\hline \multirow{6}{*}{ Causes } & Flu & $69(21.0)$ \\
\hline & Infectious disease & $61(18.6)$ \\
\hline & Surgery & $40(12.2)$ \\
\hline & Musculoskeletal disorder & $62(18.9)$ \\
\hline & Pregnancy & $41(12.5)$ \\
\hline & General (others) & $55(16.8)$ \\
\hline Age $(\operatorname{mean} \pm \mathrm{SD})$ & $(35.49 \pm 7.53)$ & \\
\hline $\begin{array}{l}\text { Duration of employment } \\
\text { (mean } \pm \mathrm{SD})\end{array}$ & $(7.53 \pm 5.63)$ & \\
\hline
\end{tabular}

Table 2. Median Numbers of Sickness Absenteeism Days According to Demographic and Occupational Characteristics

\begin{tabular}{|c|c|c|c|}
\hline Variables & & N; Median (IQR) & $P$ Value \\
\hline \multirow{2}{*}{ Age } & $<35$ & $\mathrm{~N}: 90 ; 3(1-8)$ & \multirow{2}{*}{0.11} \\
\hline & $\geq 35$ & $\mathrm{~N}: 90 ; 4(2-11)$ & \\
\hline \multirow{2}{*}{ Gender } & Male & $\mathrm{N}: 31 ; 3(2-7)$ & \multirow{2}{*}{0.73} \\
\hline & Female & $\mathrm{N}: 149 ; 4(1-10)$ & \\
\hline \multirow{2}{*}{ Marital status } & Single & $\mathrm{N}: 59 ; 3(1-9)$ & \multirow{2}{*}{0.29} \\
\hline & Married & $\mathrm{N}: 121 ; 4(2-10)$ & \\
\hline \multirow{2}{*}{ Children } & No children & $\mathrm{N}: 88 ; 3(1-8)$ & \multirow{2}{*}{0.08} \\
\hline & Children + & $\mathrm{N}: 90 ; 4(2-10)$ & \\
\hline \multirow{2}{*}{$\begin{array}{l}\text { Education } \\
\text { level }\end{array}$} & $<$ Bachelor's degree & $\mathrm{N}: 45 ; 4(1.50-10.50)$ & \multirow{2}{*}{0.69} \\
\hline & $\geq$ Bachelor's degree & $\mathrm{N}: 135 ; 3(1-9)$ & \\
\hline \multirow{2}{*}{$\begin{array}{l}\text { Employment } \\
\text { type }\end{array}$} & Contract & $\mathrm{N}: 88 ; 3(1-8)$ & \multirow{2}{*}{0.22} \\
\hline & Official & $\mathrm{N}: 91 ; 4(2-13)$ & \\
\hline \multirow{2}{*}{ Job } & Nursing group & $\mathrm{N}: 114 ; 3(1-10)$ & \multirow{2}{*}{0.77} \\
\hline & Others & $\mathrm{N}: 66 ; 3.50(2-9)$ & \\
\hline \multirow{2}{*}{ Ward } & ICU, CCU, Emergency & $\mathrm{N}: 71 ; 3(2-8)$ & \multirow{2}{*}{0.68} \\
\hline & Others & N:109; 4(1-11.50) & \\
\hline \multirow{2}{*}{ Shift work } & Rotatory & $\mathrm{N}: 87 ; 4(2-10)$ & \multirow{2}{*}{0.51} \\
\hline & Fixed & $\mathrm{N}: 93 ; 3(1-9.50)$ & \\
\hline \multirow{2}{*}{$\begin{array}{l}\text { Duration of } \\
\text { employment }\end{array}$} & $<5$ years & $\mathrm{N}: 111 ; 3(1-8)$ & \multirow{2}{*}{0.18} \\
\hline & $\geq 5$ years & $\mathrm{N}: 69 ; 4(2-12.50)$ & \\
\hline
\end{tabular}


Table 3. Correlations Between Number of Sickness Absenteeism Spells and Demographic and Occupational Characteristics

\begin{tabular}{|c|c|c|c|c|c|}
\hline Variables & & $F \leq 1$, No. $(\%)$ & F >1, No. $(\%)$ & OR; 95\%Cl & $P$ Value \\
\hline \multirow{2}{*}{ Age } & $<35$ & $56(62.2)$ & $34(37.8)$ & \multirow{2}{*}{$1.2(0.66-2.18)$} & \multirow{2}{*}{0.54} \\
\hline & $\geq 35$ & $52(57.8)$ & $38(42.2)$ & & \\
\hline \multirow{2}{*}{ Gender } & Male & $21(67.7)$ & $10(32.3)$ & \multirow{2}{*}{$1.49(0.65-3.4)$} & \multirow{2}{*}{0.33} \\
\hline & Female & $87(58.4)$ & $62(41.6)$ & & \\
\hline \multirow{2}{*}{ Marital status } & Single & $36(61)$ & $23(39)$ & \multirow{2}{*}{$1.06(0.56-2.01)$} & \multirow{2}{*}{0.84} \\
\hline & Married & $72(59.5)$ & $49(40.5)$ & & \\
\hline \multirow{2}{*}{ Children } & No children & $51(58)$ & $37(42)$ & \multirow{2}{*}{$0.87(0.48-1.59)$} & \multirow{2}{*}{0.66} \\
\hline & Children + & $55(61.1)$ & 35 (38.9) & & \\
\hline \multirow{2}{*}{ Education level } & $<$ Bachelor's degree & $27(60)$ & $18(40)$ & \multirow{2}{*}{$1.00(0.5-1.99)$} & \multirow{2}{*}{1} \\
\hline & $\geq$ Bachelor's degree & $81(60)$ & $54(40)$ & & \\
\hline \multirow{2}{*}{ Employment type } & Contract & $54(61.4)$ & $34(38.6)$ & \multirow{2}{*}{$1.08(0.59-1.98)$} & \multirow{2}{*}{0.78} \\
\hline & Official & $54(59.3)$ & $37(40.7)$ & & \\
\hline \multirow{2}{*}{ Job } & Nursing group & $74(64.9)$ & $40(35.1)$ & \multirow{2}{*}{$1.74(0.93-3.22)$} & \multirow{2}{*}{0.07} \\
\hline & Others & $34(51.5)$ & $32(48.5)$ & & \\
\hline \multirow{2}{*}{ Ward } & $\mathrm{ICU}, \mathrm{CCU}$, Emergency & $46(64.8)$ & $25(35.2)$ & \multirow{2}{*}{$1.39(0.75-2.58)$} & \multirow{2}{*}{0.29} \\
\hline & Others & $62(56.9)$ & $47(43.1)$ & & \\
\hline \multirow{2}{*}{ Shift work } & Rotatory & $57(65.5)$ & $30(34.5)$ & \multirow{2}{*}{$1.56(0.85-2.85)$} & \multirow{2}{*}{0.14} \\
\hline & Fixed & $51(54.8)$ & $42(45.2)$ & & \\
\hline \multirow{2}{*}{ Duration of employment } & $<5$ years & $73(65.8)$ & $38(34.2)$ & \multirow{2}{*}{$1.86(1.01-3.44)$} & \multirow{2}{*}{0.04} \\
\hline & $\geq 5$ years & $35(50.7)$ & $34(49.3)$ & & \\
\hline
\end{tabular}

these variables. Table 3 shows the association between the number of sickness absenteeism spells and demographic and occupational characteristics. A significant correlation was seen between duration of employment and sickness absenteeism spells $(P=0.04)$, but other factors had no significant association.

To investigate the effects of the other variables, a logistic regression model was used. Only job type was seen to have a significant correlation with sickness absenteeism episodes.

\section{Discussion}

The current study purposed to determine SAR and AFR and their associations with demographic and occupational characteristics. The highest SAR adversely affects the workplace, and managerial programs should reduce it so as to increase efficiency in the workplace.

In our study, SAR was 0.011 and AFR was 0.68 . A crosssectional study done in 2009 at a teaching hospital reported that a total of 377 (12.1\%) workers had 416 episodes of sick leave with 639 sick leave days. The frequency of sickness leave was higher among Saudi workers and females. The average frequency of absence spells was 1.1 per absentee. ${ }^{9}$ The AFR was lower in the current study, possibly because different countries may have different policies, such as easier verification of medical leave.

A cross-sectional study conducted in 2010 at Mazandaran University of Medical Sciences showed that 1200 employees left the workplace due to illness, mean days of sick leave and total days of sick absence were $2 \pm 1$ and 2571, respectively, and there was a higher frequency of sick absence among 38-41-year-olds. ${ }^{10}$ The mean age of study participants was 35 years.

The current study found that $17.2 \%$ of absentees were male and $82.8 \%$ were female. Regression analysis showed no significant relationship between gender and sickness absence. There was no association between sickness absence and gender or nationality in the Khawaja study. ${ }^{9}$ In a survey of 1509 workers from 3 public hospitals in Brazil, a higher rate of sickness absence for multiple days was seen in women and employees of a younger age. ${ }^{11}$ Another study in Iran showed that more women were sick and absent than men. ${ }^{10}$ During a study period of one year in a hospital, 8146 spells of absence and 34829 days lost due to sickness were reported. Sickness absenteeism was higher among participants who were married, female, aged from 45 to 60 , mainly untrained workers, and those who had a work history of more than ten years. The mean episodes of absence and mean days of sick leave lost per worker was statistically significant in women. ${ }^{12}$

A greater number of sick leave days (67.2\%) occurred in married absentees, but no correlation between marital status and sickness absence was seen in regression analysis. Contrary to the current study, $81.7 \%$ of sick leave days were issued to married employees in the medical staff of Mazandaran ${ }^{10}$; similarly, married women had more sickness absence in three public hospitals in Brazil. ${ }^{11}$

In Ferreira and colleagues' study in which was done in $2012,50.6 \%$ of absentees had one or more children. Having children was not a risk factor for sickness absence. Similar to the current results, having children younger than 18 years of age was not associated with fewer $(P=0.34)$ or more $(P=0.08)$ days of absence. Conversely, marital status was one of the most important factors of the absenteeism rate, mainly when the worker had children and more household duties. ${ }^{11}$

In this study, 75\% of absentees had a bachelor's degree or higher, but regression analysis disapproved any correlation between education and absenteeism. In all, 50.8\% of absentees had official employment, and no significant 
relationship between employment type and sickness absence was seen in this study. Unlike the current study, Mohseni Saravi and colleagues' findings showed that contract employees were absent more often than those with other types of employment. ${ }^{10}$ This finding is attributable to the fact that in Iran, contract workers don't worry about losing their jobs.

It seems that the main cause of sickness absence was the employee's health status; if one's health is evaluated correctly, it is not expected to be affected by variables such as gender, marital status, or educational degree, unless these variables are correlated with the subject's health condition. For example, this study found that $63.3 \%$ of sickness absenteeism was related to the nursing group, and there was a significant association between job type and sickness absence episodes. Nurses make up the majority of employees in hospitals, and because of the nursing shortage, especially in Iranian hospitals, workload and job stress are higher in this group. These psychological stresses along with exposure to different occupational hazards could have an adverse effect on one's physical health and indirectly increase sick leave.

In total, $39.4 \%$ of sick leaves occurred in the ICU, CCU, and Emergency ward, which could be explained by the heavier workload and work stress in these areas due to exposure to critically ill patients.

Employees with fixed shift work comprised $51.7 \%$ of absentees, but there was no association between type of employment and sickness absence. This is matched with the findings of another descriptive study done on 219 hospital staff members in a 500-bed nursing home. They were randomly selected from 8 out of 15 sections. Shift work had no significant relationship with other factors in any analysis. ${ }^{13}$

The major diseases causing sickness absence were flu (21\%), musculoskeletal disorders (18.9\%), and infectious diseases (18.6\%). Among the respiratory problems, 97 subjects were infected with influenza and 115 had the common cold. The current results were the same as Mohseni Saravi and colleagues' findings, in that respiratory disease $(35.5 \%)$ and skeletal disease (17.7\%) were more common than any other reason. ${ }^{10}$ Moreover, Khawaja reported the most common causes of sickness absence were respiratory infection, musculoskeletal, and digestive system diseases. ${ }^{9}$ Musculoskeletal disease was the most common reason for sick leave in Sweden and among professional nurses in Brazil. ${ }^{14,15}$ Hospital employees have different ergonomic risk factors, such as moving patients, awkward postures, and standing for long hours, which could have adverse health effects. ${ }^{16}$

\section{Conclusion}

Based on these findings, it can be concluded that factors such as the flu vaccine, providing principles of personal protection, and infection control can reduce sickness absence due to infectious disease.

The strength of this study is the use of registered data,

\section{Research Highlights}

\section{What Is Already Known?}

Sickness absenteeism represents workers' health status; therefore, it is a main public health issue. Frequent sick leave is very important for any organization, especially hospitals. HCWs are a necessary element in the effective delivery of health services to society; therefore, health problems in this group could have adverse effects on job performance and quality of patient care.

\section{What This Study Adds?}

Among groups of hospital staff, the nursing group had a higher number of sickness absence episodes. Flu, musculoskeletal disorders, and infectious diseases were the most frequent causes of sickness absence. Therefore, improvements in ergonomic and infection control programs, such as more coverage of the flu vaccine and providing principles of personal protection, can reduce sickness absence due to infectious disease.

because there was possible recall bias in self-reported sickness absence. The limitations of this study are that it investigated only one hospital and its cross-sectional design; therefore, its extension to all HCWs is limited.

In order to improve the generalizability of the current results, it is recommended that a simple study be done in other hospitals (private and public) under the supervision of an authorized unit such as the Occupational Health Department. ${ }^{16}$

\section{Authors' Contributions}

All authors contributed equally to this research.

\section{Conflict of Interest Disclosures}

The authors declare that they have no conflicts of interest.

\section{Ethical Approval}

Due to ethical considerations, the names of the employees were not mentioned publicly. This study was approved by the hospital's Ethics Committee.

\section{References}

1. North F, Syme SL, Feeney A, Head J, Shipley MJ, Marmot MG. Explaining socioeconomic differences in sickness absence: the Whitehall II Study. BMJ. 1993;306(6874):361-366. doi:10.1136/bmj.306.6874.361.

2. Schreuder JA, Roelen CA, Koopmans PC, Moen BE, Groothoff JW. Effort-reward imbalance is associated with the frequency of sickness absence among female hospital nurses: a crosssectional study. Int J Nurs Stud. 2010;47(5):569-576. doi:10.1016/j.ijnurstu.2009.10.002.

3. Hanebuth D, Meinel M, Fischer JE. Health-related quality of life, psychosocial work conditions, and absenteeism in an industrial sample of blue- and white-collar employees: a comparison of potential predictors. J Occup Environ Med. 2006;48(1):28-37. doi:10.1097/01.jom.0000195319.24750.f8.

4. Kivimaki M, Head J, Ferrie JE, Shipley MJ, Vahtera J, Marmot MG. Sickness absence as a global measure of health: evidence from mortality in the Whitehall II prospective cohort study. 
BMJ. 2003;327(7411):364. doi:10.1136/bmj.327.7411.364

5. Sepkowitz KA. Occupationally acquired infections in health care workers. Part I. Ann Intern Med. 1996;125(10):826-834. doi:10.7326/0003-4819-125-10-199611150-00007.

6. Dement JM, Epling C, Ostbye T, Pompeii LA, Hunt DL. Blood and body fluid exposure risks among health care workers: results from the Duke Health and Safety Surveillance System. Am J Ind Med. 2004;46(6):637-648. doi:10.1002/ajim.20106.

7. Fong YF, Cheng WM. Sickness Absenteeism Among Nurses of a Hospital. Hong Kong Practitioner.1991;13(5):1465-1475.

8. Wright E. Sickness absence. In: Agius R, Seaton A, eds. Practical Guide to Occupational Medicine. 2nd ed. Edward Arnold Ltd; 2005:186-219.

9. Khawaja RA, Sikander R, Khawaja AA, Jareno RJ, Halepota AT. Medically certified sickness absence among health care workers. J Pak Med Assoc. 2012;62(9):900-904.

10. Mohseni Saravi B, Kabirzadeh A, Rezazadeh E, et al. Prevalence and causes of medical absenteeism among staff (case study at mazandaran university of medical sciences: 20092010). Mater Sociomed. 2013;25(4):233-237. doi:10.5455/ msm.2013.25.233-237.

11. Ferreira RC, Griep RH, Fonseca Mde J, Rotenberg L. A multifactorial approach to sickness absenteeism among nursing staff. Rev Saude Publica. 2012;46(2):259-268. doi:10.1590/ S0034-89102012005000018.

12. Pines A, Skulkeo K, Pollak E, Peritz E, Steif J. Rates of sickness absenteeism among employees of a modern hospital: the role of demographic and occupational factors. Br J Ind Med. 1985;42(5):326-335. doi:10.1136/oem.42.5.326.

13. Cohen-Mansfield J, Rosenthal AS. Absenteeism of nursing staff in a nursing home. Int J Nurs Stud. 1989;26(2):187-194. doi:10.1016/0020-7489(89)90034-5.

14. Heijbel B, Josephson M, Jensen I, Vingard E. Employer, insurance, and health system response to long-term sick leave in the public sector: policy implications. J Occup Rehabil. 2005;15(2):167-176. doi:10.1007/s10926-005-1216-x.

15. Martinato MC, Severo DF, Marchand EA, de Siqueira HC. [Absenteeism in nursing staff an integrative review]. Rev Gaucha Enferm. 2010;31(1):160-166. doi:10.1590/S198314472010000100022.

16. Izadi n, Sadeghniiat Haghighi k, Malek m. The Results of Medical Surveillance of Health Care Workers by the First Hospital Occupational Health Clinic. J Mil Med. 2015;17(2):73-79. 